\title{
[ENTRE PAISAGENS]: DO ATELIÊ ÀS PESQUISAS ACADÊMICAS
}

\author{
Tharciana Goulart da Silva ${ }^{1}$
}

\section{Resumo}

O presente artigo aponta perspectivas de pesquisas em Arte no campo de Ensino das Artes Visuais. As investigações acadêmicas de Graduação e Pós-Graduação são fundamentadas em ações realizadas no Grupo de Pesquisa [Entre Paisagens], que tem como locus de trabalhos práticos/reflexivos o Grupo de Estudos Estúdio de Pintura Apotheke. Partindo da experiência em Arte, as Monografias e Dissertações apresentam um espaço para reflexão e discussão sobre o ser professor/artista. Como eixo teórico situam-se os escritos de Lampert (2015), Pessi (2002) e Dewey (2010).

Palavras-chave: Pesquisa em Arte, professor/artista, experiência.

\section{[BETWEEN LANDSCAPES]: FROM THE ATELIER TO ACADEMIC RESEARCH}

\begin{abstract}
This article points out perspectives of research in Art in the field of Visual Arts Teaching. The academic investigations of Undergraduate and Postgraduate Studies are based on actions taken in the Grupo de Pesquisa [Entre Paisagens] that has as a locus of practical/reflexive works the Grupo de Estudos Estúdio de Pintura Apotheke. Starting from the experience in Art, the Monographs, and Dissertations present a space for reflection and discussion about being a teacher/artist. As theoretical axis lie the writings of Lampert (2015), Pessi (2002), and Dewey (2010).
\end{abstract}

Keywords: Research in Art, teacher/artist, experience.

O Grupo de Pesquisa [Entre Paisagens] (CAPES/CNPq), vinculado ao Centro de Artes (CEART) da Universidade do Estado de Santa Catarina (UDESC), é coordenado pelas Professoras Jociele Lampert e Elaine Schimidlin, e investiga o espaço/tempo da Arte na Arte Educação. Fundado no ano de 2014, o grupo propõe diálogos entre o ser professor e o ser arista.

\footnotetext{
${ }^{1}$ Mestre em Artes Visuais na linha de pesquisa Ensino das Artes Visuais PPGAV-UDESC (2017). Universidade do Estado de Santa Cataria (UDESC).E-mail: tharcianagoulart@gmail.com.
}

Criar Educação, Criciúma, v. 7, no1, jan/jul 2018.- PPGE - UNESC 
Estar [entre paisagens] é desenvolver reflexões sobre as práticas docentes e poéticas, questionando como estas se sustentam e se cruzam. Para Lampert, o [entre] "[...] representa a busca por pesquisas, ancoradas na paisagem da experiência artística, que pode gerar outras instâncias de produção e reflexão" (2015, p. 65). A mesma autora demonstra perceber o ser professor/artista como um espaço de articulação que "direciona uma práxis de fazer artístico como pesquisa, que evidencia direcionamentos ao ensino [...]" (2015, p. 64).

Tendo como locus o Grupo de Pesquisa [Entre Paisagens], o Grupo de Estudos Estúdio de Pintura Apotheke ${ }^{2}$ vem desenvolvendo há quatro anos investigações pautadas em Arte. Os estudos realizados nesse espaço têm refletido nas pesquisas acadêmicas de Monografia e Dissertação de seus integrantes, que derivam de metodologias traçadas na experiência em Arte, como Pesquisa Baseada em Arte, Pesquisa em Arte, Cartografia, A/r/tografia e Bricolagem.

\section{Ateliê: espaço de prática e reflexão}

O Grupo de Estudos Estúdio de Pintura Apotheke, coordenado pela Professora Dr. a Jociele Lampert, é composto por alunos de Graduação, Pós-Graduação e pela comunidade, ou seja, pessoas que não necessariamente mantêm vínculo com instituições de Ensino, mas que em suas investigações desenvolvem o pensamento pictórico no campo expandido. Atualmente, acolhe vinte e dois integrantes, exercendo trabalhos nos quais envolve questões relacionadas a técnicas artísticas, estudos teóricos, desenvolvimento poético, Ensino e Aprendizagem de Artes Visuais. Assim, trata-se de um espaço onde

questões sobre Arte como experiência, sobre o lugar de quem produz e de quem ensina Arte, ou ainda de um saber/fazer competente ao artista, evocam a pesquisa/investigação sobre o modo como o ensino/aprendizagem no espaço do ateliê influenciam atitu-

\footnotetext{
${ }^{2}$ A palavra APOTHEKE tem origem grega no substantivo apotheke, que designava armazéns do porto de Atenas na Grécia Clássica; também de origem germânica, e indica a origem da palavra 'botica, boticário ou farmácia'. A escolha por esta nomenclatura decorre da percepção da botica como lugar de laboratório, de um labor experimental, o que se aproxima da proposta do grupo que traz em sua fundamentação teórica a referência de John Dewey. Neste sentido, aponta-se para Arte como Experiência, como eixo de interação entre prática e teoria, não fazendo distinção entre o saber artístico e um saber intelectual, considerando o espaço/tempo Universitário em que estamos inseridos.
}

Criar Educação, Criciúma, v. 7, no1, jan/jul 2018.- PPGE - UNESC 
des, crenças, valores, estudos e produções artísticas dos sujeitos artistas pesquisadores, envolvidos com o grupo (LAMPERT; NUNES, 2014, p. 101).

Ao longo dos anos de 2014 e 2015, estudaram-se diferentes técnicas, como Encáustica (bidimensional e tridimensional), Cianotipia, Antotipia, Suminagashi, Monotipia, Pintura a óleo, Acrílica, Aquarela, Colagem e Desenho, pautadas na relação entre a Arte e a experiência (DEWEY, 2010). Tais estudos foram ancorados em pesquisas sobre artistas referências, questões de composição, cor, poética e potencialidade da imagem enquanto Arte.

As técnicas estudadas são tradicionais, mas o modo de pensá-las e desenvolvêlas não necessitam acontecer de forma correspondente. Quando refletidos de modo contemporâneo, ressignificados no espaço/tempo, podem discorrer sobre questões atuais e abarcar formatos diferenciados. Os estudos são ainda potencializados pela poética do professor/artista que os utiliza, a qual pode colocá-los em uma nova dimensão através da atitude de pensá-los e compô-los.

O Apotheke, como programa de extensão, oferece conversas, aulas abertas e micropráticas com artistas convidados, micropráticas sobre os estudos que se realizam como Grupo e residências artísticas. Desempenhou três exposições nas quais pôde discutir sobre suas produções, oferecer ações educativas e o estudo de práticas artísticas em outros espaços além da Universidade. Em 2014, a primeira mostra ocorreu na Fundação Hassis (Florianópolis/SC), em 2015, na Galeria Pedro Paulo Vecchietti (Florianópolis/SC), e em 2016 na Galeria Agostinho Duarte da UNOCHAPECÓ (Chapecó/SC). No ano de 2015, deu-se início também a uma revista acadêmica ${ }^{3}$, a qual publica artigos, entrevistas, resenhas e traduções, procurando ampliar e desdobrar as questões de Arte e Ensino.

As ações realizadas possibilitam 0 andarilhar pela pesquisa, apontando caminhos e compartilhando inquietações sobre o ser professor/artista. O Grupo é um espaço criativo que procura ir além do fazer, pois reflete questões teóricas e poéticas ancoradas na História da Arte, no Ensino, na Aprendizagem e na Filosofia. Dentre os autores referências, estudamos John Dewey, em especial o livro Arte

\footnotetext{
${ }^{3}$ Plataforma da Revista Apotheke: http://www.revistas.udesc.br/index.php/APOTHEKE.33.
}

Criar Educação, Criciúma, v. 7, no1, jan/jul 2018.- PPGE - UNESC 
como Experiência (2010), Kandinsky, Do espiritual na arte e na pintura em particular (1996), e Josef Albers, A interação da cor (2009). Por meio desses estudos os participantes desenvolvem ensaios, projetos e pesquisas plásticas.

O Grupo de Estudos Estúdio de Pintura Apotheke demonstra a possibilidade de articulação entre a pintura e outras linguagens plásticas (englobando expressões contemporâneas). Mesmo tendo o foco sobre a pintura, sugere a compreensão do campo ampliado desta linguagem. Assim, este o Grupo evidencia a relevância de pensar o tempo e o espaço da pesquisa em Arte, e ainda se diferencia enquanto grupo de estudos por colocar em destaque a relação entre prática e teoria.

No ano de 2016, as ações aconteceram em formato diferenciado. O enfoque foi dado sobre o estudo de cor tendo como referência principal Josef Albers (2009). Albers trata especialmente sobre a interação, a relação entre as cores e as possíveis alterações ao se criar justaposições. Seus escritos propõem um aprofundamento primeiro no entendimento prático, e depois, teórico (assim, o conhecimento parte da prática), invertendo muitas vezes o que se propõe na academia.

Josef Albers objetivou seus estudos e docência sobre o sentido da visão. Em seu livro $A$ interação da cor (2009), o autor discorre sobre o assunto explícito no título da publicação, demonstrando que a visão, como percepção sensorial sobre o mundo, por vezes nos "engana". Tal engano deriva essencialmente da relatividade entre as cores e sua percepção através do espaço.

$\mathrm{O}$ autor aponta um modo de estudo de cor baseado na experimentação, em testes, justaposição, sobreposição e transparências. Dessa forma, foge do corriqueiro sobre as cores e suas misturas. Trazendo a questão da percepção visual, pondera sobre os efeitos cromáticos interativos, demonstrando a relevância de tal estudo para aquele que manipula e pensa a cor.

Assim, Josef Albers propõe soluções para problemas de ordem do pictórico por meio da pesquisa prática e posteriormente sobre a teoria. É somente pela reflexão da prática realizada, relacionada aos saberes, que a Aprendizagem pautada na experiência torna-se possível.

Josef Albers desenvolveu sua metodologia amparado em um distanciamento da Escola Tradicional, incisiva sobre os saberes dos educandos. $\mathrm{O}$ artista e professor, 
desse modo, ancorou seu Ensino na questão da Filosofia da Experiência trazida por Dewey (2010), sugerindo maneiras de estudar e assim testar e perceber a cor.

A filosofia de Dewey permite delinear articulações na perspectiva do professor/artista e assim trazer reflexões também situadas no contexto do Ensino. Por isso, pode ser percebida como "um pragmatismo aliado a uma filosofia educacional que pede posturas ao professor" (PESSI, 2002, p. 19), e também posturas ao artista.

Para o reconhecimento da relevância de experiências ao Ensino e Aprendizagem "[...] é preciso, primeiramente, entender e insistir em acreditar no ser humano como quem quer experienciar o mundo" (PESSI, 2002, p. 20). Ao acreditar no Outro compreendendo-o como alguém que entrelaça experiências passadas e futuras, a fim de desenvolver uma consciência sobre o vivido, o Ensino se faz real e efetivo, e assim "é possível o deslocamento para um contexto mais amplo da sociedade" (PESSI, 2002, p. 25).

Por reconhecer o [entre] como recinto potente, um 'disparador' e um dispositivo de inquietação, o Grupo Apotheke trabalha em uma perspectiva aproximada a teoria de Albers e Dewey (2010), enfatizando a relevância da experiência em Arte para quem aprende e ensina.

\section{Lugares de transbordamento: do ateliê às pesquisas acadêmicas}

O Estúdio de Pintura Apotheke, por proporcionar ações investigativas que derivam sobre o espaço de prática e reflexão nas Artes Visuais e seu Ensino, tem sido evidenciado enquanto embasamento conceitual nos trabalhos acadêmicos de seus integrantes nos âmbitos da Graduação e Pós-Graduação.

As pesquisas trazem percursos e momentos de produções artísticas e docentes. Suas provocações e sentidos residem, na prática, no que é vivido e ressignificado. Ou seja, o conhecimento é organizado pela experiência de produção e construção desses trabalhos.

Conforme o pensamento deweyano, a experiência é delineada por repousos e pausas (DEWEY, 2010). É nesses espaços de tempo que a reflexão acontece e, sem a conscientização do vivido, a mudança real contínua torna-se inacessível. 
Portanto, há um tempo de 'maturação' entre o vivido no Grupo e a transformação dessa experiência para as investigações em Artes Visuais que deambulam sobre o Ensino.

As vertentes conceituais, os formatos das Dissertações e TCCs, assim como suas apresentações, fazem refletir sobre como se deseja que a pesquisa chegue ao Outro, como o experienciado é partilhado enquanto conhecimento. Desse modo, questionam como a Pesquisa em Arte transborda no espaço acadêmico enquanto visualidade.

A Dissertação $A$ monotipia no campo expandido: reflexões sobre Arte e Arte/Educação contemporânea, apresentada por Leandro Serpa no ano de 2015, demonstra uma pesquisa que pondera sobre a experiência com a técnica monotipia enquanto campo expandido e suas possibilidades de abertura junto à poética e ao Ensino. Discorre sobre a experiência artística como um dos modos de fundamentar a prática docente. Em sua apresentação final, Serpa retorna ao espaço de ação do Grupo Apotheke, o ateliê de pintura da Universidade (UDESC), criando uma instalação com os seus trabalhos de modo a evidenciar o processo criativo.

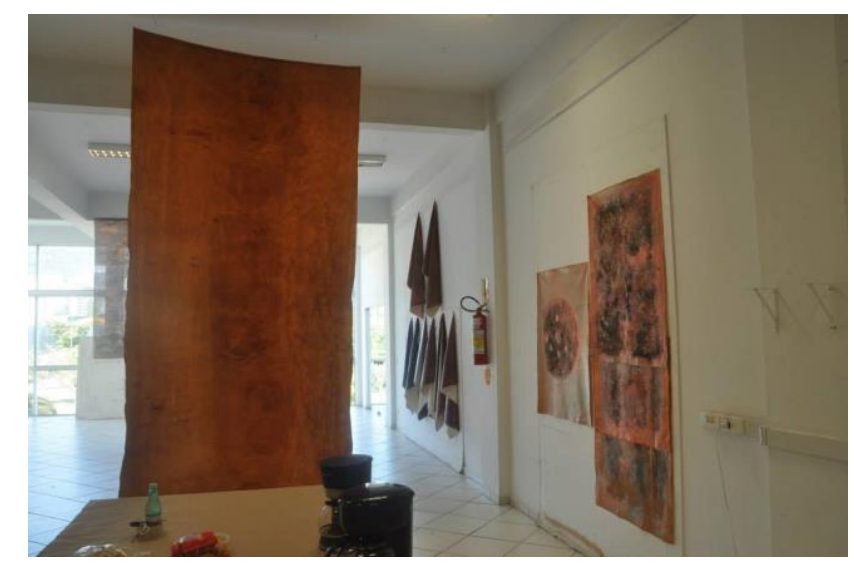

Apresentação da Dissertação de Leandro Serpa.

Fonte: Acervo do Grupo de Estudos Estúdio de Pintura Apotheke.

Fábio Wosniak, na Dissertação $A$ poética na prática de um pedagogo: experiência sobre aprender Artes Visuais através da pintura, fundamentou-se sobre o estudo da Cartografia e investigou como é desenvolvida a Aprendizagem em Artes Visuais por meio da pintura. A pesquisa de campo foi realizada através de sua atuação no Grupo de Estudos Estúdio de Pintura Apotheke. Baseado em sua Criar Educação, Criciúma, v. 7, no1, jan/jul 2018.- PPGE - UNESC 
experiência e trajetória, o autor evidencia a relação entre a prática artística e a Educação.

Luciana Finco Mendonça, com a Dissertação O lugar das Artes Visuais na Escola: reflexões sobre práticas pedagógicas diferenciadas (2016), desenvolvendo como metodologia a Pesquisa Baseada em Arte, investigou práticas diferenciadas de Ensino no espaço da escolar. Para compreendê-las, realizou uma experiência de coleta em que propôs residência artística na Escola Lauro Müller, situada no centro de Florianópolis (SC). A residência contou com 13 artistas que interviram e criaram a partir do ambiente.

Derivando sobre o espaço da Educação Básica, a Dissertação parte de sua apropriação como forma de evidenciar o contexto no processo criativo do professor/artista. A apresentação final da Dissertação de Mendonça, realizada no ateliê de pintura da Universidade, retomou as imagens da Escola, das produções dos artistas e de suas produções poéticas e docentes criando um mapa/instalação.

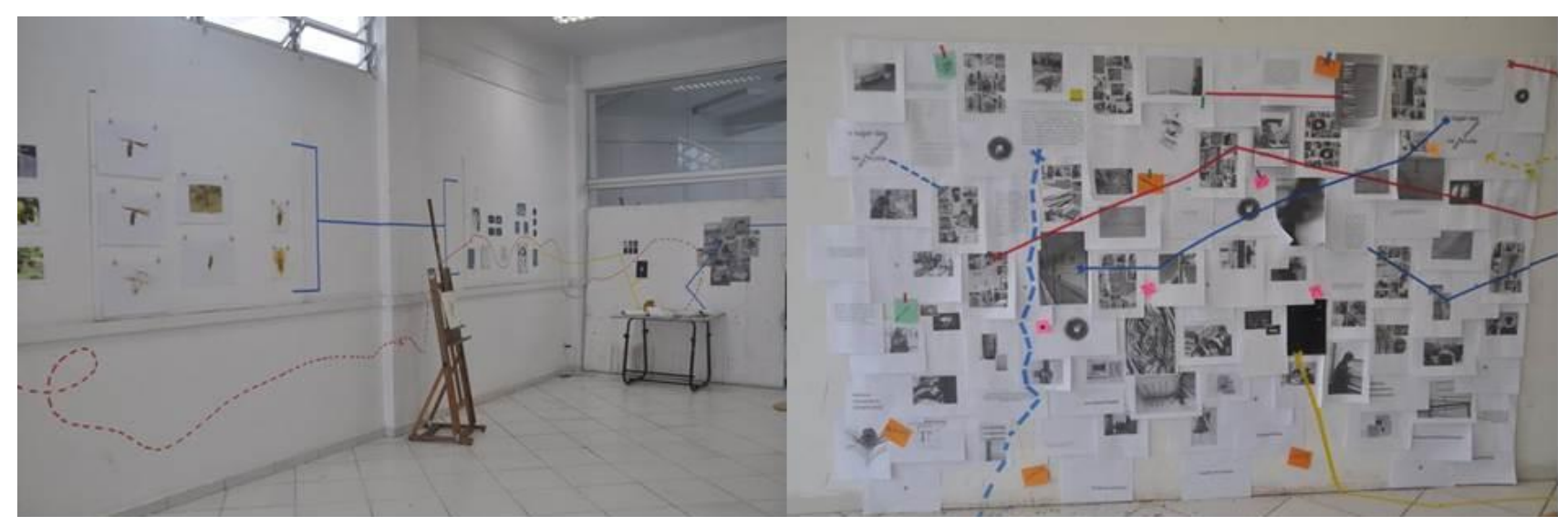

Apresentação da Dissertação de Luciana Mendonça.

Fonte: Acervo do Grupo de Estudos Estúdio de Pintura Apotheke.

Diário de Professor/Artista: a prática como foco de investigação no Ensino das Artes Visuais (2016) é a Dissertação de Márcia Figueiredo. A autora, partindo da Bricolagem como metodologia, investigou diários de artistas e desenvolveu seu próprio diário. Situando-se como professora/artista viajante, reflete sobre seus percursos entre Curitiba (local onde residia) e Florianópolis (onde realizou seu Mestrado). Fundamentada nas práticas oportunizadas pelo Estúdio de Pintura 
Apotheke, retoma o espaço de reflexão por meio da visualidade, tendo como eixo teórico principal o livro Arte como Experiência de John Dewey (2010).

José Carlos da Rocha, com a Dissertação Experiências poéticas em Arte Educação com adolescentes no centro de internação feminina (2017), baseado da a/r/tografia enquanto bússola metodológica, realizou uma investigação refletindo sobre o Ensino das Artes Visuais em espaço diferenciado. No Centro de Internação Feminina de Florianópolis efetuou uma coleta de dados com adolescentes entre $15 \mathrm{e}$ 21 anos. Para isso, utilizou-se de técnicas artísticas tais como Monotipia, Cianotipia, Desenho e Colagem, como modo de emergir as memórias das internas e desenvolver o Ensino das Artes Visuais.

[Entre] Imagens Transitórias, Dissertação de Mestrado apresentada no ano de 2017 por Tharciana Goulart da Silva, questiona como a prática artística pode sustentar a prática docente na sala de aula. A Pesquisa em Arte como vertente metodológica é ressignificada na produção plástica e investigação docente. Para as percepções sobre o duplo - professor/artista - desenvolve uma pesquisa teórica e prática sobre a técnica de Antotipia $^{4}$ (tendo como eixo poético coleções de insetos), a qual aprendeu no ano de 2014 no Grupo de Estudos de Pintura Apotheke. Após esta inserção no espaço prático e reflexivo, a autora realiza experiência no espaço escolar.

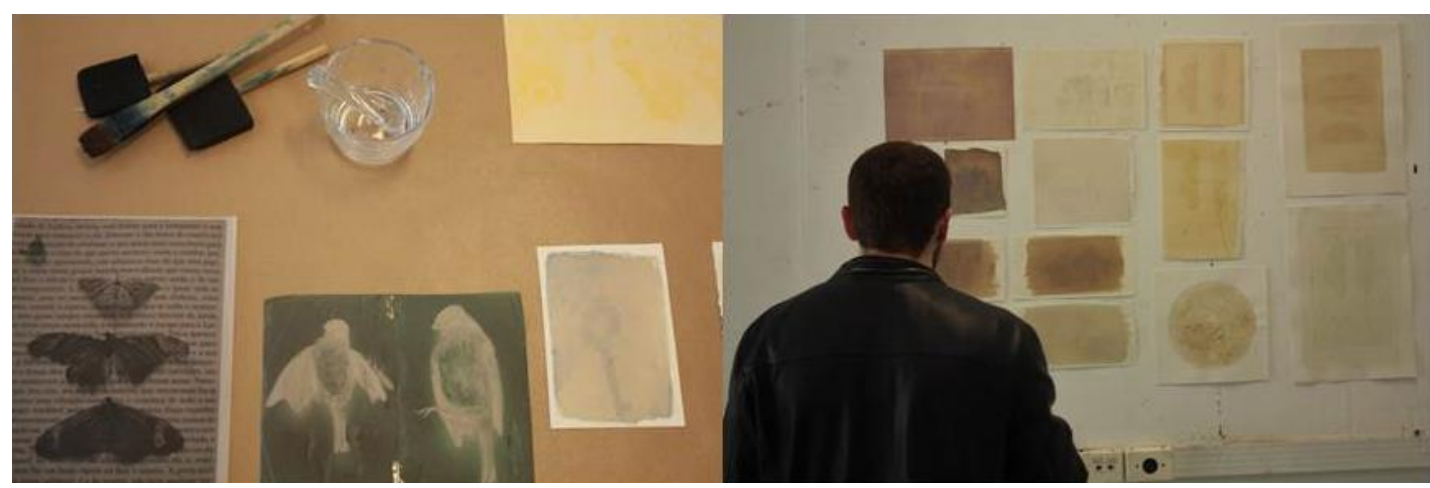

Apresentação da Dissertação de Tharciana Goulart da Silva.

Fonte: Acervo do Grupo de Estudos Estúdio de Pintura Apotheke.

\footnotetext{
${ }^{4}$ Antotipia (também nomeada Phytotypes ou Anthotype) é um processo fotográfico alternativo e histórico desenvolvido no ano de 1842 por Sir John Herschel (1792-1871).
}

Criar Educação, Criciúma, v. 7, no1, jan/jul 2018.- PPGE - UNESC 


\section{CRIAR EDUCAÇÃO}

Revista do Programa de Pós-Graduação em Educação - UNESC
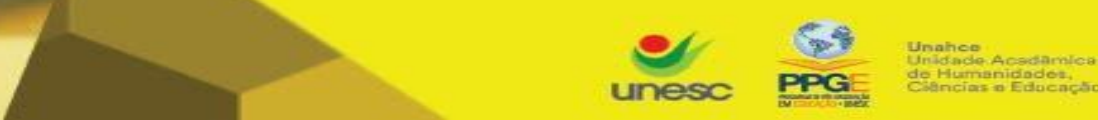

ediunesc

O Trabalho de Conclusão de Curso Quando o limite não existe: processo, poética, arte contemporânea, de autoria de Rita Eger, propõe um formato diferenciado que enfatiza sua prática artística. Desenvolvendo a Pesquisa em Arte, Eger cria um trabalho em "camadas poéticas" dividido em cinco livros nos quais fala de seu processo criativo a partir das obras.

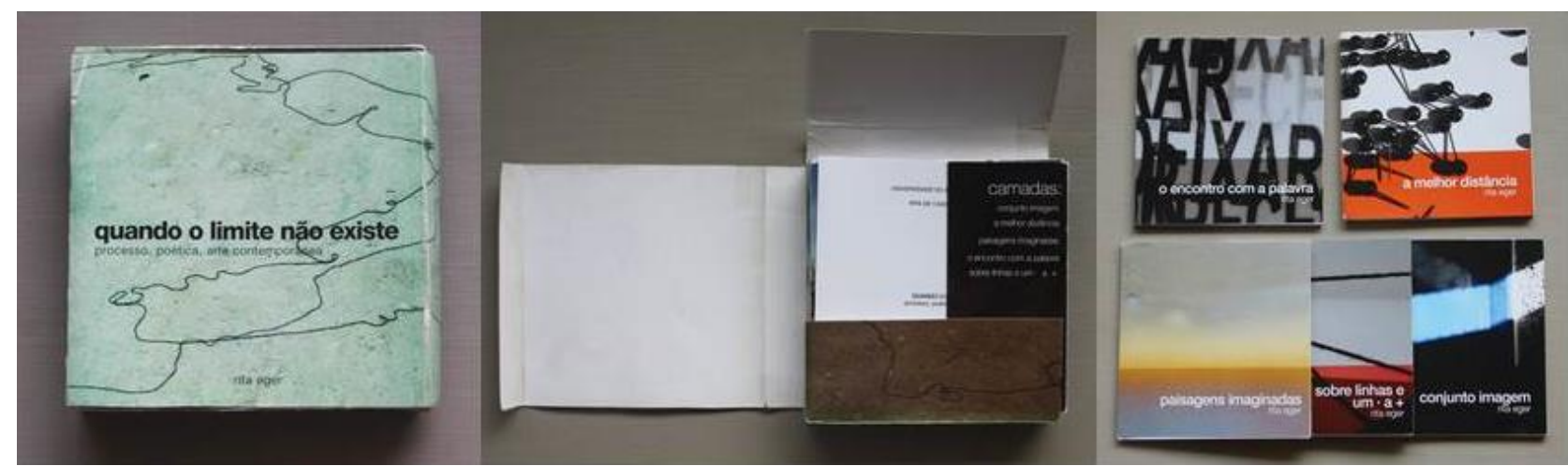

Monografia de Rita Eger: Quando o limite não existe: processo, poética, arte contemporânea. Fonte: Acervo do Grupo de Estudos Estúdio de Pintura Apotheke.

Diários: processos educativos e artísticos (2015) é o Trabalho de Conclusão de Curso de Tharciana Goulart da Silva. O TCC, que traz as coleções como linha poética, é dividido em duas partes contendo pesquisas teóricas e práticas e um material artístico-pedagógico. O diário, como espaço para reflexão sobre atuações nas Artes Visuais, é colocado enquanto lugar que propõe autoavaliação e reflexão crítica sobre as experiências que tangenciam o professor/artista.

Criar Educação, Criciúma, v. 7, no1, jan/jul 2018.- PPGE - UNESC 


\section{CRIAR EDUCAÇÃO}

Revista do Programa de Pós-Graduação em Educação - UNESC

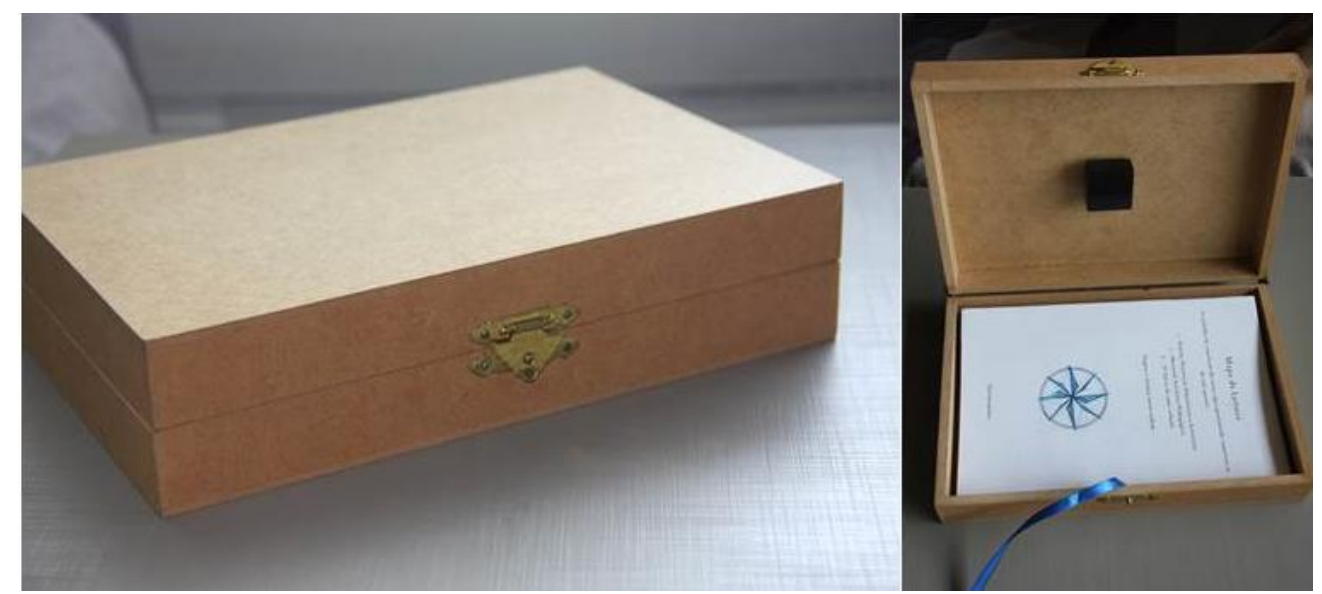

Monografia de Tharciana Goulart: Diários: processos educativos e artísticos. Fonte: Acervo do Grupo de Estudos Estúdio de Pintura Apotheke.

Para lembrar de, Monografia de Esther Lorizolla Cordeiro, demonstra a relevância de diários na formação docente. No entanto, o trabalho não discorre sobre diários, mas é o próprio diário de uma licenciada em Artes Visuais. Assim, Para lembrar de tem folhas soltas e pode ser lido em qualquer ordem ou alterado; e é um escrito que mescla as relações entre Arte, vida e docência.

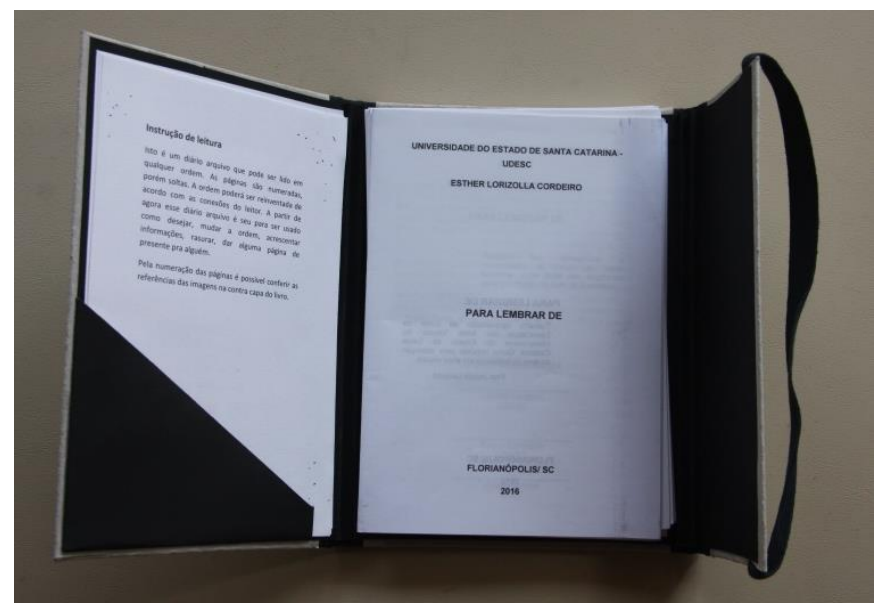

Monografia Para lembrar de, trabalho de conclusão de curso de Esther Lorizolla Cordeiro. Fonte: Acervo do Grupo de Estudos Estúdio de Pintura Apotheke.

O Grupo de Estudos Estúdios de Pintura Apotheke é evidenciado nas pesquisas aqui apresentadas como lugar que nutre a relação entre a prática e a reflexão na Arte. As pesquisas derivam do ateliê, dos processos de experiênciar para ensinar.

Criar Educação, Criciúma, v. 7, n1, jan/jul 2018.- PPGE - UNESC 
De diferentes modos e com distintas interrogações as investigações dos Mestres e Graduados colocam em discussão o espaço e a construção do professor/artista, não necessariamente como alguém que deve ter uma prática em Arte (enquanto processo artístico), mas como sujeito que parte de questões entrelaçadas dos olhares artísticos e educativos, poéticos e docentes, e assim rompe espaços instituídos para ressignificá-los através do pensamento estético.

\section{Pesquisas em Arte: o professor/artista como sujeito caminhante}

O [entre] se constrói como recinto investigativo e formativo do professor/artista. A pesquisa em Arte, quando situada no Ensino das Artes Visuais, direciona-se ao processo criativo, seja este o traçado de um planejamento de Ensino ou desenvolvimento de uma obra. Nesse sentido, deriva de um espaço de ação e reflexão sobre as práticas do professor/artista.

A pesquisa em Arte contempla um caráter processual, pois parte dos acontecimentos, e por isso reside sobre os processos investigativos. Seu objeto de estudo advém do ato criativo. É a ação de fazer/planejar, mas também inquietações e desdobramentos de seu decorrer enquanto conceito e olhar poético.

As experiências do professor/artista, o que the toca no sensível, são algo pessoal que fazem parte do seu olhar sobre o mundo e o processo de criação. Por isso, interferem na maneira como uma metodologia de pesquisa é construída. As possibilidades metodológicas e as escolhas sobre os caminhos percorridos durante o processo criativo são variadas, mas também são singulares, pois

[...] o percurso criador, ao gerar uma compreensão maior do projeto, leva o artista a um conhecimento de si mesmo. Daí o percurso criador ser para ele, também, um processo de autoconhecimento e, consequentemente, autocriação, no sentido de que ele não sai de um processo do mesmo modo que começou: a compreensão de suas buscas estéticas envolve autoconhecimento (SALLES, 2014, p. 65).

Desse modo, por mais que pairem diversas maneiras de realizar a pesquisa em Arte, o traçado de uma metodologia é algo único e subjetivo, que compreende o processo artístico e docente. Em razão disso, requer desenvolvimentos, 
regularidades, e assim proporciona o autoconhecimento e a construção da subjetividade.

A pesquisa em Arte, aporta sobre problemáticas diferentes de outras áreas de pesquisa (talvez mais reconhecidas tradicionalmente), mas isso não significa que, ao realizar uma pesquisa em Arte, deve-se necessariamente excluir outras possibilidades de pesquisas que são comuns em campos não dominados por esta. Pois a técnica e a poética em relação ao trabalho podem exigir desdobramentos intelectuais e metodológicos por parte do professor/artista, e a pesquisa sobre Arte torna-se um embasamento para produção na Arte e na Arte Educação.

O professor/artista, ao traçar escolhas, confere uma direção ao seu trabalho, caminho construído ao longo do processo, mas que não necessariamente elimina as ações do acaso enquanto elemento para apropriar-se ou do erro como acontecimento com possibilidade propulsora. Ao construir-se uma metodologia própria de pesquisa, "muito mais importante do que achar respostas é saber colocar questões" (REY, 2002, p. 127). O hibridismo da pesquisa em Arte, que por vezes tangencia outras áreas de estudos, propõe desafios ao pesquisador, nos quais seu processo deve ser crítico e reflexivo para não recair apenas sobre o fazer.

Refletindo sobre a metodologia da pesquisa em Arte enquanto um caminho, um percurso criador que também se desenvolve em seu decorrer, Fervenza coloca:

Os caminhos são muitos [...] São inevitáveis as bifurcações, os desvios, as pontes, as derivas do andar. Muitas vezes jogamos pedras no escuro, para que elas nos indiquem a presença ou ausência dos abismos. O caminho está indissoluvelmente ligado ao caminhante e seu andar. Resumindo: os caminhos em questão se fazem à medida que caminhamos (FERVENZA, 2002, p. 67).

O objeto de estudo desta metodologia do caminhar, do professor/artista enquanto sujeito caminhante atento e que pode perceber seu processo criativo enquanto rede (SALLES, 2014), também é construído em seu desenvolver. Novas proposições são percebidas no decorrer da pesquisa, por isso esta é baseada no sentido de processo.

Desse modo, o [entre], conceito norteador do Grupo de Pesquisa [Entre Paisagens] situa-se como um ambiente de ação para os meandros das pesquisas Criar Educação, Criciúma, v. 7, nำ, jan/jul 2018.- PPGE - UNESC 
apresentadas. Perceber-se no espaço do [entre] não quer dizer criar zonas fechadas de estudos, mas abrir horizontes para as experiências. Este reverbera sobre os modos de fazer, de pensar e atuar. Sua singularidade reside na inquietude do pensamento estético e docente.

\section{Referências:}

DEWEY, John. Arte como experiência. São Paulo: Martins Fontes, 2010.

FERVENZA, Helio. Olho mágico. In: BRITES, B.; TESLER, E. (Orgs.). O meio como ponto zero: metodologia de pesquisa em Artes Plásticas. Porto Alegre: Universidade/UFRGS, 2002.

LAMPERT, Jociele. [Entre paisagens] ou sobre 'ser' artista professor. In: Ecologias Inventivas: experiências nas/das paisagens. GUIMARAES, L. B. [et al.]. 1. ed. Curitiba: CRV, 2015.

LAMPERT, Jociele; NUNES, Carolina Ramos. Entre a prática pedagógica e a prática artística: reflexões sobre Arte e Arte Educação. Revista Digital do LAV, Santa Maria, v.7, n. 3, set./dez. 2014. Disponível em: <https://periodicos.ufsm.br/revislav/article/view/14258>. Acesso em: jan. 2016.

PESSI, Maria Cristina Alves dos Santos. Experiência Estética: Construindo Professores de Arte. Revista Nupeart, Florianópolis, v. 1, set. 2002. Disponível em:

<http://www.revistas.udesc.br/index.php/nupeart/article/view/3032>. Acesso em: 30 ago. 2016.

REY, Sandra. Por uma abordagem metodológica da pesquisa em artes visuais. In: BRITES, B.; TESLER, E. (Orgs.). O meio como ponto zero: metodologia de pesquisa em Artes Plásticas. Porto Alegre: UFRGS, 2002.

SALLES, Cecilia Almeida. Redes da Criação: construção da obra de arte. 2. ed. São Paulo: Horizonte, 2014. 